\title{
$M y b$-Independent Macrophages: A Family of Cells That Develops with Their Tissue of Residence and Is Involved in Its Homeostasis
}

\author{
Elisa Gomez Perdiguero and Frederic Geissmann \\ Centre for Molecular and Cellular Biology of Inflammation (CMCBI), Division of Immunity, Infection, \\ and Inflammatory Diseases, King's College London, London WC2R 2LS, United Kingdom
}

Correspondence: frederic.geissmann@kcl.ac.uk

\begin{abstract}
In most metazoans, all tissues contain phagocytes "in residence," generally termed "macrophages" in vertebrates. In contrast to myeloid cells produced continuously by the bone marrow (BM), tissue-resident macrophages develop during embryogenesis together with their tissue of residence, and persist in adulthood, independently of hematopoietic stem cells and the transcription factor $M y b$. They therefore represent an independent lineage from blood monocytes, dendritic cells, and monocytes/macrophages that are recruited to tissues during inflammation. Tissue-resident macrophage functions are yet to be completely defined. They all share the ability to scavenge toxic compounds, lipids, microorganisms, and dead cells and contribute to tissue remodeling, via phagocytosis and the production of growth factors. In contrast, the production of inflammatory mediators seems to be more associated with BM-derived cells. Tissue-resident macrophages and BM-derived myeloid cells thus differ in developmental origin and functions; the term "macrophages" could be reserved for $M y b$-independent-resident macrophages to avoid confusion. A genetic and molecular dissection of resident macrophage functions will reveal their roles in tissue metabolism and the maintenance of homeostasis independently of the extravasation of inflammatory leukocytes, and in the control of the recruitment of BM-derived cells in overt inflammation.
\end{abstract}

Elie Metchnikoff studied the development and functions of "phagocytes," cells capable of engulfing particules, which are observed through all phyla, from protozoan to mammals. In triploblastic organisms (having three germinal layers: ecto-, meso-, and endoderm), phagocytes are mesodermal cells that have retained the ability to engulf foreign bodies, microorganisms, and neighboring cells. They contribute to tissue renewal and maintenance (as shown for Echinoderm larvae [Metchnikoff 1884b]) and respond to wounding and pathogens (Metchnikoff 1884b). In the tree of life, the tissue phagocytes are observed before the emergence of the vascular system. In animals with a vascular system, Metchnikoff suggested that such "extravascular" or "connective tissue" phagocytes, which he termed "Macrophages," participate in tissue remodeling and in the recruitment of the vascular leukocytes in response to tissue damage (Metchnikoff 1884a).

Since then, many attempts were made to characterize their origin and their relationship with blood leukocytes. The most prevalent model, developed in the 1970s, integrated macrophages into the concept of the "mononuclear phagocyte system" (MPS), based on (1) common morphological criteria, (2) common functions-professional phagocytes that attach firmly to glass surface, and (3) the hypothesis that they share a common origin in the bone marrow (BM), from hematopoietic stem and progenitor cells (HSPCs) (van Furth and Cohn 1968; van Furth et al. 1972). The MPS thus proposed that myeloid precursors from the BM differentiate into monocytes that circulate in the blood and populate tissues as macrophages in the steady state and during inflammation. In accordance with this model, circulating monocytes can extravasate from the blood and give rise to inflammatory macrophages in response to inflammatory cues and other signals, such as tumor progression and wound healing (Geissmann et al. 2003; Serbina and Pamer 2006). The classical dendritic cell (DC) lineage (Meredith et al. 2012), initially described by Ralph Steinman, also shares with monocytes a common BM progenitor that circulates in the blood and seed lymphoid tissues (Fogg et al. 2006; Liu et al. 2007; Onai et al. 2007). The MPS model allowed progress into the study of the function of macrophages and DCs, using monocyte-derived cells as a model.

However, a large number of observations are not in accordance with the MPS model in regard to macrophages. A population of macrophages appears in the embryo before hematopoietic stem cells (HSCs) are detected (Sorokin et al. 1992). During embryogenesis, macrophages in human, mice, and zebrafish were shown to develop bypassing the monocyte stage (Naito et al. 1996; Herbomel et al. 1999; Naito 2008). Tissue-resident macrophages are not affected in monocytopenic mice (Yamada et al. 1990; Naito et al. 1996) and do not exchange between parabiotic mice (Merad et al. 2002; Ajami et al. 2007). After irradiation and BM graft, tissue macrophages are only partially "replaced," and this depends on the level of tissue damage, rather than the BM replacement (Mildner et al. 2007). In addition, several populations of tissue-resident macrophages, such as Langerhans cells in the epidermis, Kupffer cells in the liver, microglia in the central nervous 
system, and macrophages from the peritonea and pleura, proliferate in situ in steady state and in inflammation (Sawyer et al. 1982; Miyauchi and Hashimoto 1987; Yamada et al. 1990; Chorro et al. 2009; Davies et al. 2011; Jenkins et al. 2011). Pulse-labeling at E7.25-7.5 (before hematopoietic stem cell emergence) in Runx1$M E R-i C r e-M E R$; R26LSL-YFP embryos results in the labeling of the microglia in adults (Ginhoux et al. 2010).

Collectively, these observations suggested that tissue macrophages might not meet the criteria to be included in the MPS. Indeed, they develop from embryonic progenitors distinct from HSPCs, persist in adult independently of the transcription factor $M y b$ (Schulz et al. 2012), and renew independently of BM-derived cells and monocytes (Schulz et al. 2012; Hashimoto et al. 2013; Yona et al. 2013). We here review experimental evidence investigating the origin of macrophages and discuss the existence and consequences of two models of differentiation of myeloid cells that coexist through embryonic development and adulthood.

\section{EXPERIMENTAL EVIDENCE FOR A $M y b$ - INDEPENDENT HSC-INDEPENDENT LINEAGE OF TISSUE MACROPHAGES}

\section{$M y b$-Independent Tissue Macrophages Self-Renew Independently from the BM}

Gene invalidation in the mouse has allowed the identification of genes that are required for the generation and/ or maintenance of progenitors and hematopoietic stem cells. Among these genes, the transcription factor $M y b$ is required for development of HSPCs and all HSPC-derived monocytes, macrophages, and DCs (Mucenski et al. 1991). Myb-deficient mice present a phenotype reminiscent of that of Runx 1-deficient mice, but do not present hemorrhage and die later with anemia between E15 and E17 (Mucenski et al. 1991; Mukouyama et al. 1999; Sumner et al. 2000; Schulz et al. 2012). Although Myb-deficient AGM and fetal liver (FL) do not present HSC activity, macrophages are present in normal numbers in E10.5 yolk sac (YS) (Schulz et al. 2012), suggesting that $M y b$ is dispensable for YS hematopoiesis (Sumner et al. 2000; Schulz et al. 2012). At later stages of embryonic development, two populations of tissue myeloid cells can be defined on the expression of F4/80 and CD11b. As expected for HSC-derived myeloid cells, CD11 b ${ }^{\text {bright }}$ myeloid cells in all organs and CD117/c-Kit ${ }^{+}$progenitors in the FL were absent in $M y b$-deficient animals. However, tissue macrophages, defined as F4/80 ${ }^{\text {bright }}$, were present in all organs examined, such as the liver, skin, brain, spleen, pancreas, lungs, and kidneys (Schulz et al. 2012).

In adult mice, the loss of $M y b$ by conditional deletion also causes failure of hematopoiesis (Lieu and Reddy 2009; Schulz et al. 2012). Mx1-Cre mice allow a widespread expression of Cre in all cell types upon Poly(I:C) administration. Targeted disruption of the $M y b$ gene in Cd45.2; MxlCre; Myb flox/flox mice leads to a rapid depletion of the HSC pool and of blood monocytes and granulocytes, and a syngeneic $C d 45.1 \mathrm{Myb}^{+/+} \mathrm{BM}$ engrafts without irradiation. Monocytes and granulocytes, as well as CD11 b ${ }^{\text {bright }}$ myeloid cells in the spleen, liver, kidneys, and pancreas, are completely replaced by donor BMderived cells, whereas microglia, epidermal LCs, Kupffer cells, and a large proportion of F4/80 ${ }^{\text {bright }}$ in other tissues remain of the host, $M y b$-deficient, origin 3 mo after transplantation of a wild-type BM (Schulz et al. 2012). Two independent groups have confirmed that tissue-resident macrophages self-renew independently from monocytes and BM progenitors using expression of Cre driven by CX3CR1 (Yona et al. 2013) or by following repopulation of myeloid cells and tissue-resident macrophages after genetic depletion (Hashimoto et al. 2013). Previous studies had shown that depletion of blood monocytes by strontium-89 does not affect the number of resident peritoneal and alveolar macrophages (Sawyer et al. 1982) and Kupffer cells (Yamada et al. 1990) nor their proliferation capacity (Sawyer et al. 1982; Yamada et al. 1990).

Therefore, tissue "resident" macrophages develop in the absence of $M y b$ and HSPCs and persist in adult tissues independently of HSPCs (Fig. 1).

\section{Myb-Independent Macrophages Originate from a CSF1-R Progenitor Generated in the YS, Are Largely FLT3-Independent, and Are Capable of Proliferation}

In an unsupervised hierarchical clustering analysis of gene expression arrays from E10.5 YS macrophages, E16.5 F4/80 ${ }^{\text {bright }}$ macrophages, and E16.5 CD11b bright myeloid cells from $M y b$ wild-type (WT) and $M y b$-deficient embryos, F4/80 bright tissue macrophages clustered with E10.5 YS macrophages. The Csf1 receptor (Csf1r) was part of the $M y b$-independent F4/80 bright signature, whereas Flt3, the FLT3L receptor, was part of the $M y b$ dependent F4/80 low signature (Schulz et al. 2012). Therefore, Csf1r and Flt3 were used to investigate the persistence of YS-derived macrophages into adulthood using fate-mapping strategies.

Early expression of Csflr in YS precursors and the availability of a tamoxifen-dependent Csfrl-CRE mouse line (Csfrl-MER-iCre-MER) (Qian et al. 2011) allow us to identify in adults the progeny of $\mathrm{CSF} \mathrm{R}^{+}$cells labeled during early development. In utero administration of TAM in E8.5 Csfr1-MER-iCre-MER; R26LSL-YFP embryos results in YFP expression by adult $M y b$-independent macrophages, whereas $M y b$-dependent HSC-derived cells such as blood leukocytes are not labeled (Schulz et al. 2012). Thus, E8.5 CSF1R ${ }^{+}$precursors give rise to tissue macrophages, such as microglia, Langerhans cells, Kupffer cells, and macrophages in the spleen, lung, pancreas, and kidneys that persist in adults (Fig. 1). They are most likely generated in the YS, because they are labeled before the HSC emergence from the aorto-gonado-mesonephros (AGM). Whether these progenitors differentiate in situ in the YS or whether they migrate into the FL, where they amplify and differentiate before seeding other tissues, is still an open question (discussed below).

Flt3 is expressed on multipotent hematopoietic progenitors (Buza-Vidas et al. 2011), MDPs (Auffray et al. 


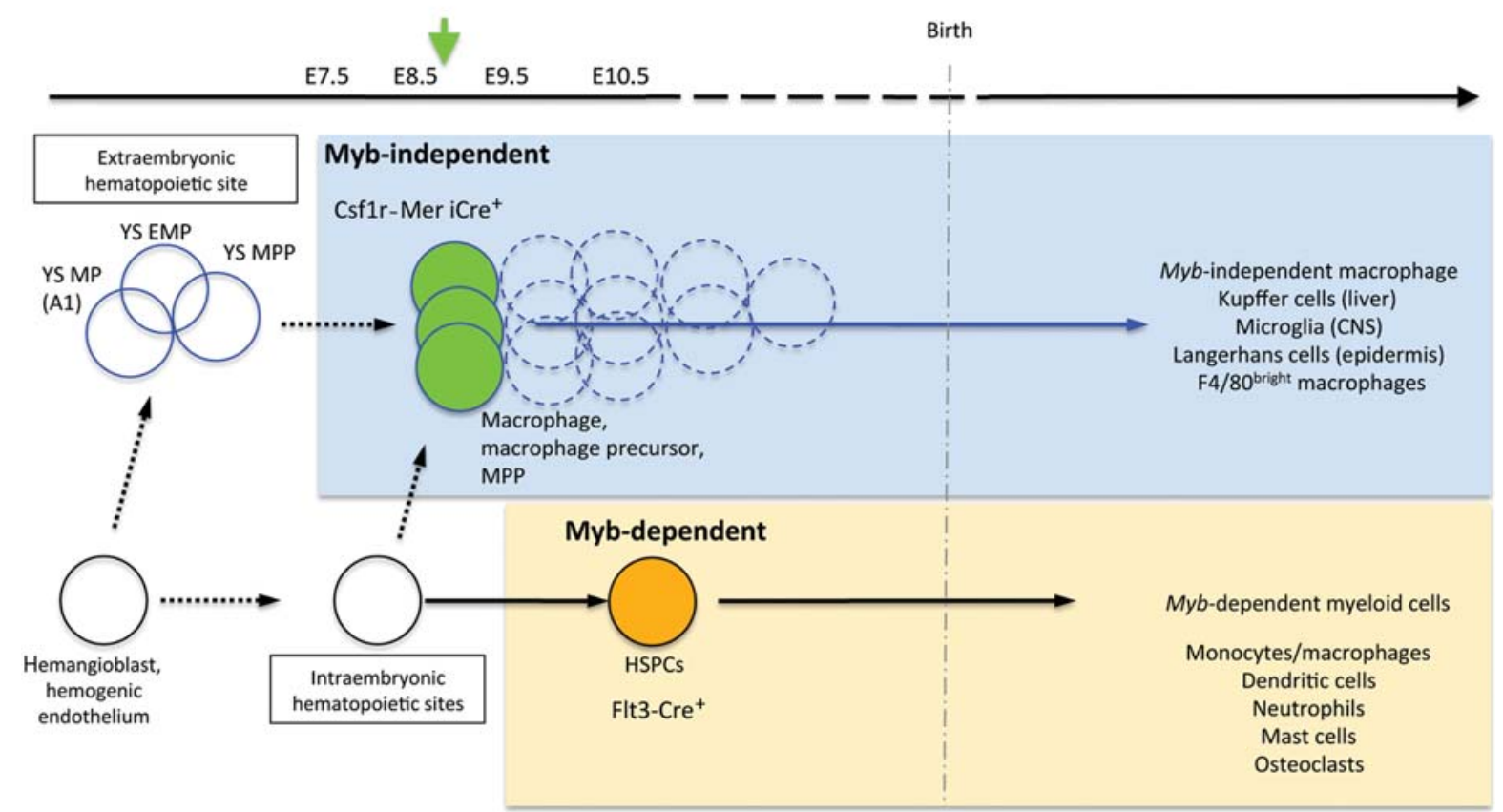

Figure 1. Differentiation of myeloid cells. Model for the development of the two myeloid lineages: the $M y b$ independent (blue) and HSC dependent (orange). The origin of HSCs and yolk sac (YS) progenitors from hemangioblasts or hemogenic endothelium is still a source of controversy (as reviewed in Ueno and Weissman 2010). During embryonic development, hematopoiesis in the YS comprises EMPs, macrophage-restricted progenitors (MP), and multipotent progenitors (MPP) (Palis et al. 2001; Bertrand et al. 2005). Pulse labeling at E8.5 using TAM (green arrow) in Csf1r-meriCremer; Rosa-YFP F1 embryos labels macrophages/macrophage precursors (green circles) presumably in the YS. These macrophages/macrophage precursors continue to be generated during development (dashed circles) in the YS or the FL. Progeny of E8.5-E9.5 CSF1R ${ }^{+}$cells in adults include liver Kupffer cells, epidermal Langerhans cells, brain microglia, and F4/80 bright macrophages in other tissues. A second wave of hematopoiesis within the embryo proper gives rise to $M y b$-dependent FLT3 ${ }^{+}$HSPCs that expand in the fetal liver and can be fate mapped using Flt3-Cre mice (orange circle). Their myeloid progeny in adults includes monocytes, classical dendritic cells, and PDCs, neutrophils, mast cells, and osteoclasts.

2009), cDC progenitor (Onai et al. 2007), and common lymphoid progenitors in the BM (Buza-Vidas et al. 2011). The progeny of FLT3 ${ }^{+}$progenitors can be detected by expression of YFP in the F1 progeny of Flt3-Cre $\times$ R26LSL-YFP mice (Srinivas et al. 2001; Benz et al. 2008). YFP expression is overall restricted to blood leukocytes and to tissue $M y b$-dependent CD1 $1 \mathrm{~b}^{\text {high }}$ myeloid cells (Schulz et al. 2012), indicating that the development of $M y b$-independent macrophages occurs largely independently of $\mathrm{FLT}^{+}$precursors (Fig. 1).

Persistence of $M y b$-independent macrophages in adulthood could be explained by cell proliferation. Kupffer cells filled with phagocytized beads are present 3 mo after intravenous administration of beads and mitotic beadfilled Kupffer cells can also be detected (Bouwens et al. 1986), suggesting that Kupffer cells have a long life span and can proliferate even after phagocytosis. In humans, epidermal Langerhans cells were also shown to remain of donor (limb) origin $10 \mathrm{yr}$ after limb graft (Kanitakis et al. 2004, 2011). This is compatible with results from several recent studies that have re-investigated the proliferation capacities of resident macrophages and confirmed earlier observations that microglia, epidermal LCs, and macrophages in the liver, peritoneum, and pleura can proliferate during inflammation and in the steady state (Bouwens et al. 1986; Lawson et al. 1992; Klein et al. 2007; Shankaran et al. 2007; Chorro et al. 2009; Thored et al. 2009; Davies et al. 2011; Jenkins et al. 2011). In humans, there is also evidence of proliferation of tissue-resident macrophages, such as Kupffer cells (Antoniades et al. 2012), alveolar macrophages (Golde et al. 1974; Pforte et al. 1993), microglia (Gomez-Nicola et al. 2013), and Langerhans cells (Kanitakis et al. 2011), both during the steady state and in inflammation.

\section{The Case of the BM Radiation Chimera}

BM transplantation results in a very high level of chimerism for granulocytes, monocytes, classical DCs, and plasmacytoid DCs, indicating that they are short-lived, being replaced continually from BM precursors (Fogg et al. 2006; Onai et al. 2007; Auffray et al. 2009; Liu et al. 2009) (reviewed in Geissmann et al. 2010). It also leads to a partial, relatively inefficient, and variable level of chimerism of tissue macrophages. The latter seems to be dependent on the local tissue damage and/or macrophage death induced by the irradiation protocol, and the presence of a T-cell allogeneic response by donor cells. Irradiation and/or conditioning therapies induce cell death, tissue damage, and alteration of the basement mem- 
brane-for example disruption of the blood-brain barrier-and promote inflammation (Diserbo et al. 2002; Kaya et al. 2004; Barcellos-Hoff et al. 2005; Kierdorf et al. $2013 b$ ). This is responsible for the recruitment of donor blood leukocytes in host tissues, akin to some inflammatory processes. For example, in a model of encephalitis where microglial cells are not killed by irradiation, monocytes are transiently recruited but do not ultimately contribute to the resident microglial pool and vanish, whereas resident microglia proliferate and then persist following remission (Ajami et al. 2011). In BM radiation chimera, local brain irradiation is indeed required for the monocyte recruitment into the parenchyma (Mildner et al. 2007). In mice irradiated with a head protection and receiving a syngeneic BM transplant, monocytes fail to enter the brain parenchyma and microglia remains entirely of the host origin (Mildner et al. 2007). Similarly, Kupffer cells and epidermal Langerhans cells can remain of the host origin for extended periods of time after syngeneic BM transplantation (Katz et al. 1979; Perreault et al. 1984; Merad et al. 2002; Ajami et al. 2007).

Therefore, the irradiation chimera represents a useful tool to manipulate BM-derived leukocytes, but may not inform on the biology of tissue-resident macrophagesfirst because they are not of BM origin and also because irradiation induces cell death among tissue cells and their associated macrophages, creates inflammation, and recruits inflammatory cells. Whether recruited BM cells may functionally replace the resident macrophages when the latter are partially killed by irradiation is an open debate in the field and is briefly discussed below. Parabiosis studies have been very useful to investigate the contribution of BM to tissue macrophages and exposed some experimental issues associated with irradiation (Merad et al. 2002; Ajami et al. 2007; Liu et al. 2007). However, parabiosis studies are considered unethical in several countries. BM transplantation following genetic depletion of hematopoietic stem cells by conditional inactivation of $M y b$ (Schulz et al. 2012) may be a useful tool in this regard.

\section{HSCS-DERIVED $M y b$-DEPENDENT MYELOID CELLS: MONOCYTES AND DENDRITIC CELLS}

In contrast to resident tissue macrophages, adoptive transfer experiments and analysis of syngeneic BM transplantation have clearly shown that blood leukocytes, the classical DC lineage (Meredith et al. 2012), and PDCs develop from BM-derived HSCs. Extensive work has clarified the relationship between DC and monocyte lineages and identified their respective precursors in the blood and BM in the steady state (Fogg et al. 2006; Liu et al. 2007, 2009; Onai et al. 2007). Monocytes, DCs, and granulocytes develop from a common myeloid progenitor (CMP) (Akashi et al. 2000). A monocyte/macrophage and DC precursor (MDP) (Fogg et al. 2006) gives rise to monocytes and to the common DC precursor (CDP) (Onai et al. 2007; Liu et al. 2009). Of note, the development of monocytes and, to some extent, DCs also depends on the growth factor receptor CSF1R (Sasmono et al. 2003; MacDonald et al. 2005), and Csflr deficiency led to a reduced number of circulating monocytes (Dai et al. 2002). Flt3- and Flt3L-deficient mice have shown their critical role in the differentiation of cDCs and PDCs (McKenna et al. 2000; Waskow et al. 2008) but appeared to be dispensable for the development of monocytes.

\section{Monocytes as Effector Cells}

Monocytes are a heterogeneous population in regard to shape, size, and function (reviewed in Grage-Griebenow et al. 2001). In mice, at least two monocyte subsets have been identified. The Ly6C ${ }^{+}$"inflammatory" subset of blood monocytes, an equivalent to human CD14 ${ }^{+}$monocytes (Geissmann et al. 2003; Cros et al. 2010), extravasate in infected and inflamed tissues where they produce reactive oxygen species (ROS), iNOS, and cytokines and contribute to T-cell activation or polarization (Serbina et al. 2008; Soudja et al. 2012). CCR2-mediated signaling is important for the release of $\mathrm{Ly} 6 \mathrm{C}^{+}$monocytes from the $\mathrm{BM}$ into the blood and their recruitment to inflammation sites (Serbina and Pamer 2006; Tsou et al. 2007).

The Ly6C ${ }^{\text {lo }}$ subset of monocytes and their human putative counterparts (CD14 ${ }^{\mathrm{dim}}$ ) (Cros et al. 2010) patrol the vasculature (Auffray et al. 2007), survey the endothelium, scavenge intraluminal debris, and can orchestrate the neutrophil-mediated necrosis of endothelial cells in response to a danger signal (Carlin et al. 2013). They are also equipped with a full set of Fc receptors involved in the uptake of immune complexes (Biburger et al. 2011).

Instead of being intermediates between the BM and tissue macrophages, Ly $6 \mathrm{C}^{+}$and Ly $6 \mathrm{C}^{\text {lo }}$ blood monocytes rather appear to be bona fide effector cells in inflamed tissues and within the vasculature, respectively.

\section{Dendritic Cells}

DCs are specialized in processing and presenting antigens to elicit specific T-cell effector functions. They are found in both lymphoid and nonlymphoid organs. Because many macrophage subsets express class II antigen and because blood monocytes can stimulate $T$ cells in vitro, the distinction between DCs and macrophage is sometimes blurred. However, as outlined above, the classical DC lineage and plasmacytoid DCs are BM-derived cells with a short half-life (Liu et al. 2009; Meredith et al. 2012).

Recent studies on human immunodeficiencies have contributed to the understanding and the identification of transcription factors critical for their development. Patients carrying IRF8 and GATA-2 mutations present severe immunodeficiencies and a complete lack of circulating monocytes and DCs, although tissue macrophages appear to be normal (Dickinson et al. 2011; Hambleton et al. 2011).

One particular case is that of epidermal Langherans cells, which are currently classified as DCs, but which do not appear to be important for T-cell responses, develop from $M y b$-independent embryonic progenitors, and self-renew in adults (Merad et al. 2002; Chorro and Geissmann 2010). 


\section{THE ORIGINS OF $M y b$-INDEPENDENT MACROPHAGES AND $M y b$-DEPENDENT MYELOID CELLS}

\section{Different Developmental Waves of Progenitors with Different Hematopoietic/Myeloid Potential}

During mouse embryogenesis, hematopoiesis occurs in spatially and temporally distinct sites. Hematopoietic progenitors are generated both at extraembryonic and intraembryonic sites, whereas HSCs are generated only intraembryonically. Hematopoietic progenitors and HSCs are capable of circulating and colonizing the YS and the FL, whereas HSCs expand only in the FL. Thus, hematopoiesis during embryonic development cannot be simplified into a YS versus FL hematopoiesis.

The first hematopoietic cells appear in blood islands from the extraembryonic YS shortly after embryonic day (E) 7-7.5. Different progenitors have been proposed to emerge in the YS, primitive erythroid progenitors, macrophage-restricted progenitors, erythromyeloid progenitors (EMPs) (Bertrand et al. 2005), and high-proliferativepotential colony-forming cells (HPP-CFC) (Palis et al. 2001). The first one is called primitive, because they develop into large erythroblasts that express both embryonic and adult hemoglobins. The latter, EMPs and HPPs, are detected in the YS at E8.25 and E8.5, respectively, and subsequently differentiate in situ and migrate to the FL where they differentiate (Palis et al. 2001), and can be detected as early as E9 (Kieusseian et al. 2012). This second phase is termed "definitive" hematopoiesis in regard to its erythroid component, which produces smaller cells that express only adult hemoglobins. Macrophages generated from the EMPs enter the embryo before the first appearance of HSCs, between E9.5 and E10.5 (Naito et al. 1996; Sasmono et al. 2003; Bertrand et al. 2005; Rae et al. 2007). At E10.5, macrophages are found abundantly throughout the embryo (Schulz et al. 2012) before any monocyte can be detected, and they do not develop through a monocyte intermediary (Naito et al. 1996; Bertrand et al. 2005).

HSCs are defined - and distinguished from other progenitors - by their capacity to perform long-term repopulation (LTR) of all leukocyte lineages when transplanted into a conventional irradiated recipient mouse. Within the embryo proper, HSCs emerge from the AGM region (starting at E10.5) (Muller et al. 1994) and from the umbilical and vitelline arteries (Zovein et al. 2010) and migrate to the FL, where they expand and differentiate from E12.5 before definitive hematopoiesis begins to shift to the BM. The embryonic BM anlage is already colonized at E15 (before bone formation) and active lymphopoeisis starts there at E17, 3-4 d after colonization (Delassus and Cumano 1996). Several groups have attempted to pinpoint the specific site and time when HSC can be detected within the embryo properly. Pioneering work by Dzierzak showed that the AGM region contained the progenitors endowed with long-term reconstitution (LTR) capacity at E10.5 (Muller et al. 1994). Such in vivo grafting experiments revealed also that the P-Sp/AGM but not the YS contained a pluripotent hematopoietic potential
(Medvinsky and Dzierzak 1996; Cumano et al. 2001). Recently, Ana Cumano's group has identified immature HSCs (imHSCs) that are generated at E9-9.5 in the paraaortic splanchnopleura (P-SP), a structure that later evolves into the AGM region (Kieusseian et al. 2012): imHSCs migrate into the FL at E10, maturate into HSCs, and contribute to the adult HSC pool (Kieusseian et al. 2012). Such imHSCs are able to reconstitute NK-deficient animals but not conventional animals, because of their lack of MHC class I expression.

In summary, the hematopoietic precursors generated in the extra- and intraembryonic sites differ in their differentiation and renewal potentials. In the current model, only precursors generated in the intraembryonic compartment are endowed with lymphoid potential, and, among them, the imHSCs and HSCs provide in vivo long-term multilineage reconstitution of the hematopoietic compartment, whereas those from the YS provide only short-term myeloid reconstitution (Cumano et al. 1996, 2001).

\section{$M y b$-Independent Macrophages May Originate from Extraembryonic Progenitors}

Results from pulse-labeling of $\mathrm{CSF} \mathrm{R}^{+}$progenitors and/or macrophages at E8.5 and the requirement of Myb for HSCs maintenance (Mucenski et al. 1991) suggest that the progenitors that give rise to the $M y b$-independent lineage are generated in the YS. In support, it has been suggested that microglia arise from EMp progenitors in the YS (Kierdorf et al. 2013a). However, it is important to note that YS-generated progenitors seed the FL (Palis et al. 2001) as early as E9 (Kieusseian et al. 2012), which is also the site where $M y b$-dependent HSCs proliferate and differentiate from E11. Therefore, the FL probably represents a niche where the progenitors of $M y b$-independent macrophages and $M y b$-dependent HSCs probably coexist and expand, although a fate-mapping analysis of YS and HSC-derived hematopoietic cells within the FL has not yet been published. Work is needed to identify the progenitors from which $M y b$-independent macrophages develop, their differentiation potential, and the anatomical niches where they expand in vivo.

Although the simplest hypothesis is that $M y b$-independent macrophages originate from early YS hematopoietic progenitors distinct from intraembryonic hematopoietic stem cells, the intraembryonic sites not only generate HSCs or imHSCs, but also release multipotent progenitors without LTR activity into the circulation. P-Sp and, later, the AGM region are sources of such intraembryonic multipotent hematopoietic progenitors at E8.5 (Godin et al. 1993, 1995; Medvinsky et al. 1993; Muller et al. 1994).

Reciprocally, there is still a controversy on the origin of HSCs, and the restriction of YS precursors to primitive erythromyelopoeisis is debated (Ueno and Weissman 2010). Transplantion of E9 YS cells into the YS cavities of synchronic embryos allows the detection of donor-derived spleen colonies in secondary transplant recipient (Weissman et al. 1978; Ueno and Weissman 2010). In addition, E9.0 YS cells repopulated erythroid, lymphoid, and myeloid lineages long-term upon transplantation into 
newborn recipient animals (Yoder and Hiatt 1997). High proliferative hematopoietic precursors have also been reported in the YS before they can be detected in the blood or the embryo proper (Palis et al. 2001). Endothelial cells from E9.5 YS were shown to generate all blood cell types, including lymphocytes, suggesting that the YS endothelium may be a source of multipotent HSCs (Nishikawa et al. 1998).

It is of note that the blood circulation between the YS and the embryo is established very early at the eight-somite stage (E8-8.25) and therefore precursors can pass through the circulation from one site to the other, hampering efforts to study independently both pools of progenitors. In organotypic cultures of YS and P-Sp harvested before circulation, the progenitors have different potentials (i.e., YS progenitors have no lymphoid potential). Shortly after the start of circulation, P-Sp precursors can seed the YS, and cells of both origins would colonize the FL (Cumano et al. 1996). In accordance, mutant mice without circulation between both sites, because of lack of blood vessel formation ( VE-Cadherin-deficient embryos), present erythroid and myeloid but no lymphoid potential within the YS (Rampon and Huber 2003). However, in apparent contradiction with these reports, hematopoietic progenitors are decreased at E9.5 in the embryo, but unaffected in the YS of $N c x 1^{-/-}$mice, which die atE10, and have blood vessels but no cardiac contraction (Lux et al. 2008).

In summary, although available data suggest that $M y b$ independent, HSC-independent macrophage originate from extraembryonic progenitors, their intraembryonic origin cannot be excluded. It is therefore important to keep in mind that FL hematopoiesis should not be equated to fetal HSC-derived hematopoiesis and a fortiori to adult BM hematopoiesis, and that YS hematopoiesis cannot be opposed to FL hematopoiesis. Fate-mapping strategies or transplantation experiments are useful to assess the potential of such progenitors but do not allow drawing quantitative conclusions. Identifying novel transcription factors regulating $M y b$-independent myelopoeisis would help to investigate in vivo the development and biology of these cells.

\section{BM-Derived Myeloid Cells and $M y b$-Independent Macrophages Have Different Functions}

$M y b$-independent macrophages and $M y b$-dependent myeloid cells may mediate distinct roles in response to tissue damage and infection (Fig. 2). In contrast to monocytes recruited to the inflamed brain, which produce inflammatory mediators and appear to correlate with disease progression and poor outcome (Ajami et al. 2011), microglia neither activate NF- $\mathrm{B}$ signaling nor secrete inflammatory mediators in exacerbated tissue inflammation. Rather, they seem to protect against neuronal death (Saijo et al. 2009). Similarly, lung macrophages have been proposed to respond to infection-induced tissue damage rather than to the infection itself (Jamieson et al. 2013). Kupffer cells, the $M y b$-independent macrophages of the liver, accumulate in necrotic areas of liver failure patients and may release anti-inflammatory mediators, whereas recruited monocytes may exacerbate tissue inflammation (Antoniades et al. 2012). Compatible with this hypothesis

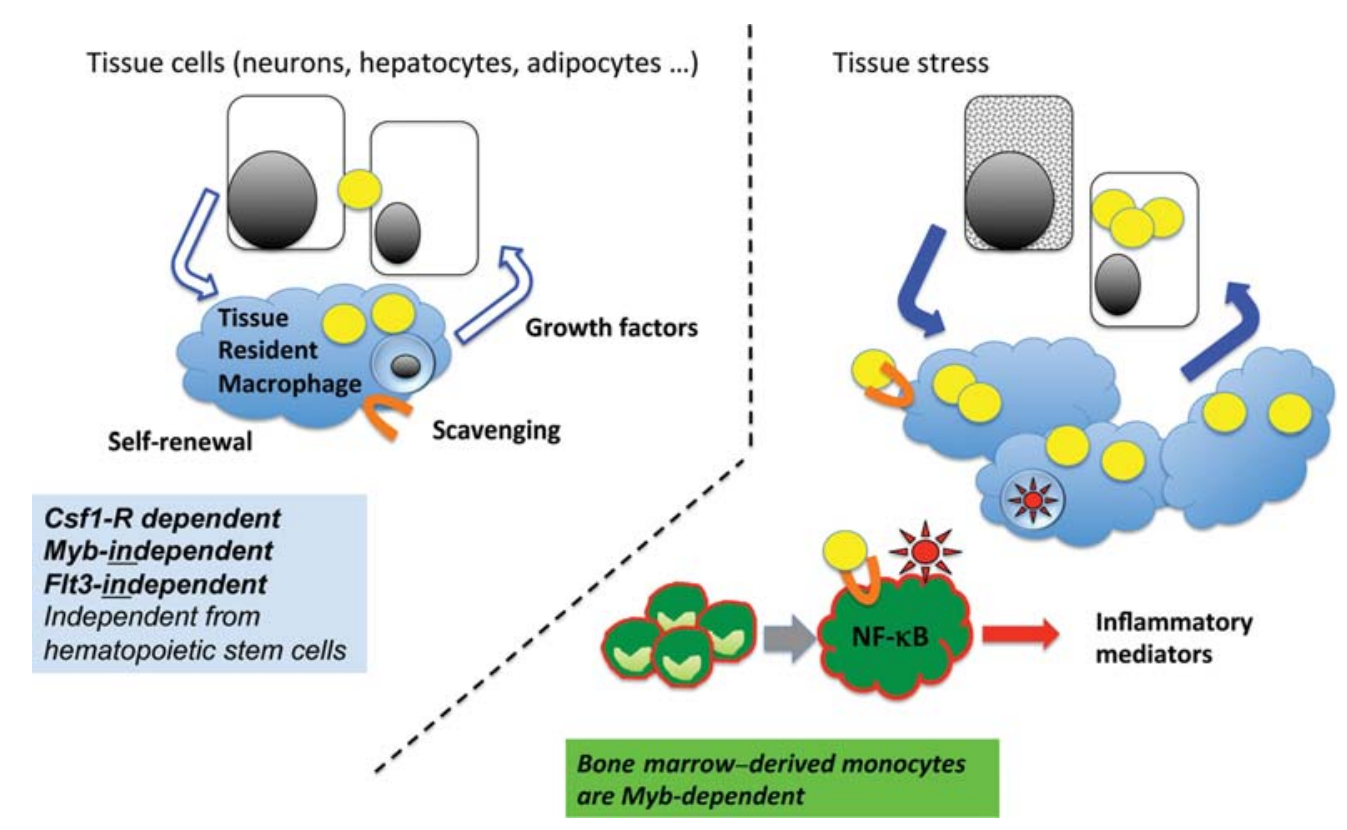

Figure 2. Functions of $M y b$-independent macrophages versus BM-derived myeloid cells. $M y b$-independent tissue resident macrophages are present in all adult tissues examined, develop from CSF1 ${ }^{+}$embryonic precursors independently of HSCs, and self-renew through local proliferation. In homeostatic (left panel) and stressed (right panel) conditions, they "sense" the tissue microenvironment by scavenging lipids, dead cells, and microorganisms, and they interact with the tissue cells (e.g., neurons, adipocytes, and hepatocytes) through production of growth factors and other signals (blue arrow). In response to a stress such as infection, lipid-rich diets, and wound healing (right panel), $M y b$-dependent monocytes can also be recruited into peripheral tissue, where they produce inflammatory mediators through NF- $\mathrm{KB}$ activation. 
is the observation that in patients undergoing BMT, irradiation leads to the slow "replacement" of tissue macrophages by monocyte-derived cells in the lung (Thomas et al. 1976), whereas in the alveoli, the repopulating cells have a different morphology and fail to respond to a Candida challenge (Winston et al. 1982), suggesting that tissue-resident alveolar macrophages and BM-derived cells have different functions.

They may also have different responses in situation of metabolic imbalance. Kupffer cells in the liver (Bieghs et al. 2010) and peritoneal macrophages (Li et al. 2004) uptake lipid and become "foamy" in a high-fat diet. This is also the case of BM-derived monocytes/macrophages, at least in vitro. However, although lipid uptake by BM-derived monocytes was shown to activate NF-кB signaling possibly through toll-like receptors (TLRs), resulting in the secretion of proinflammatory mediators such as TNF, Il-1b, Cxcl10, and CXCL9 (Moore and Tabas 2011; Biswas and Mantovani 2012), peritoneum F4/80 bright macrophages in contrast did not activate TLR-4 and NF-кB signaling and did not secrete proinflammatory molecules in response to a high-fat diet (Spann et al. 2012). This suggests that $M y b$-independent macrophages and BM-derived myeloid cells may present distinct responses to the same metabolic stimulus, here an excess of tissue lipids. This is in accordance with the proposition by R. Medzhitov that tissue-resident macrophages are responsible for an adaptive response to tissue stress or malfunction - which he termed parainflammation - intermediate between the basal homeostatic state and a classic inflammatory response where leucocyte extravasate (Medzhitov 2008).

Because $M y b$-independent macrophages develop within their tissue of residence and accompany it through development and adult life, they may play a role in morphogenesis and the maintenance of homeostasis. Microglia play an important role in the homeostasis of the surrounding neurons, by monitoring and pruning synapses (Wake et al. 2009; Paolicelli et al. 2011), phagocytozing dead cells during development and adulthood, and responding to local brain injury (Davalos et al. 2005; Nimmerjahn et al. 2005). As professional scavengers, macrophages could be seen as a sensor of the metabolic state of the tissue and its variations and provide growth factors accordingly and other mediators to tissue cells (Fig. 2).

Of note, whether the "pro-homeostatic" responses of macrophages are ultimately beneficial or detrimental in situation of chronic stress, such as, for example, a prolonged lipid-rich diet, remains to be investigated (Medzhitov 2008).

\section{CONCLUSIONS}

Macrophages and DCs are present in all tissues and are critical effectors and regulators of immune responses. The data reviewed here challenge the classical view that the MPS is a population of BM-derived cells that develops from HSCs along distinct differentiation pathways in response to internal and external cues. In contrast, we define a lineage of $M y b$-independent macrophages, alongside BM-derived inflammatory cells, which consti- tute tissue-resident macrophages and may contribute to tissue homeostasis and instruct tissue response to stress or malfunction. It will thus be important to characterize the molecular and cellular mechanisms that allow the development and maintenance of the macrophage networks, mediate their activation, and underlie their functions.

\section{AUTHORS' CONTRIBUTIONS}

E.G.P. wrote the first draft and E.G.P. and F.G. discussed, revised, and edited the manuscript.

\section{ACKNOWLEDGMENTS}

F.G. is the Arthritis Research UK Chair of Inflammation Biology, at King's College London. This work was funded by grants from the Medical Research Council, UK (no. MRC G0900867) and from the European Research Council (no. ERC-2010-StG-261299 MPS2010) to F.G.

\section{REFERENCES}

Ajami B, Bennett JL, Krieger C, Tetzlaff W, Rossi FM. 2007. Local self-renewal can sustain CNS microglia maintenance and function throughout adult life. Nat Neurosci 10: 15381543.

Ajami B, Bennett JL, Krieger C, McNagny KM, Rossi FM. 2011. Infiltrating monocytes trigger EAE progression, but do not contribute to the resident microglia pool. Nat Neurosci 14: $1142-1149$.

Akashi K, Traver D, Miyamoto T, Weissman IL. 2000. A clonogenic common myeloid progenitor that gives rise to all myeloid lineages. Nature 404: 193-197.

Antoniades CG, Quaglia A, Taams LS, Mitry RR, Hussain M, Abeles R, Possamai LA, Bruce M, McPhail M, Starling C, et al. 2012. Source and characterization of hepatic macrophages in acetaminophen-induced acute liver failure in humans. Hepatology 56: 735-746.

Auffray C, Fogg D, Garfa M, Elain G, Join-Lambert O, Kayal S, Sarnacki S, Cumano A, Lauvau G, Geissmann F. 2007. Monitoring of blood vessels and tissues by a population of monocytes with patrolling behavior. Science 317: 666-670.

Auffray C, Fogg DK, Narni-Mancinelli E, Senechal B, Trouillet C, Saederup N, Leemput J, Bigot K, Campisi L, Abitbol M, et al. 2009. $\mathrm{CX}_{3} \mathrm{CR} 1^{+} \mathrm{CD} 115^{+} \mathrm{CD} 135^{+}$common macrophage/DC precursors and the role of $\mathrm{CX}_{3} \mathrm{CR}_{1}$ in their response to inflammation. J Exp Med 206: 595-606.

Barcellos-Hoff MH, Park C, Wright EG. 2005. Radiation and the microenvironment-Tumorigenesis and therapy. Nat Rev Cancer 5: $867-875$.

Benz C, Martins VC, Radtke F, Bleul CC. 2008. The stream of precursors that colonizes the thymus proceeds selectively through the early $\mathrm{T}$ lineage precursor stage of T-cell development. J Exp Med 205: 1187-1199.

Bertrand JY, Jalil A, Klaine M, Jung S, Cumano A, Godin I. 2005. Three pathways to mature macrophages in the early mouse yolk sac. Blood 106: 3004-3011.

Biburger M, Aschermann S, Schwab I, Lux A, Albert H, Danzer H, Woigk M, Dudziak D, Nimmerjahn F. 2011. Monocyte subsets responsible for immunoglobulin $\mathrm{G}$-dependent effector functions in vivo. Immunity 35: 932-944.

Bieghs V, Wouters K, van Gorp PJ, Gijbels MJ, de Winther MP, Binder CJ, Lutjohann D, Febbraio M, Moore KJ, van Bilsen $\mathrm{M}$, et al. 2010. Role of scavenger receptor A and CD36 in dietinduced nonalcoholic steatohepatitis in hyperlipidemic mice. Gastroenterology 138: 2477-2486, e2471-2473.

Biswas SK, Mantovani A. 2012. Orchestration of metabolism by macrophages. Cell Metab 15: 432-437. 
Bouwens L, Baekeland M, De Zanger R, Wisse E. 1986. Quantitation, tissue distribution and proliferation kinetics of Kupffer cells in normal rat liver. Hepatology 6: 718-722.

Buza-Vidas N, Woll P, Hultquist A, Duarte S, Lutteropp M, Bouriez-Jones T, Ferry H, Luc S, Jacobsen SE. 2011. FLT3 expression initiates in fully multipotent mouse hematopoietic progenitor cells. Blood 118: 1544-1548.

Carlin LM, Stamatiades EG, Auffray C, Hanna RN, Glover L, Vizcay-Barrena G, Hedrick CC, Cook HT, Diebold S, Geissmann F. 2013. Nr4al-dependent Ly6 $\mathrm{C}^{\text {low }}$ monocytes monitor endothelial cells and orchestrate their disposal. Cell 153: $362-375$.

Chorro L, Geissmann F. 2010. Development and homeostasis of 'resident' myeloid cells: The case of the Langerhans cell. Trends Immunol 31: 438-445.

Chorro L, Sarde A, Li M, Woollard KJ, Chambon P, Malissen B, Kissenpfennig A, Barbaroux JB, Groves R, Geissmann F. 2009. Langerhans cell (LC) proliferation mediates neonatal development, homeostasis, and inflammation-associated expansion of the epidermal LC network. J Exp Med 206: 30893100 .

Cros J, Cagnard N, Woollard K, Patey N, Zhang SY, Senechal B, Puel A, Biswas SK, Moshous D, Picard C, et al. 2010. Human $\mathrm{CD} 14^{\mathrm{dim}}$ monocytes patrol and sense nucleic acids and viruses via TLR7 and TLR8 receptors. Immunity 33: 375-386.

Cumano A, Dieterlen-Lievre F, Godin I. 1996. Lymphoid potential, probed before circulation in mouse, is restricted to caudal intraembryonic splanchnopleura. Cell 86: 907-916.

Cumano A, Ferraz JC, Klaine M, Di Santo JP, Godin I. 2001. Intraembryonic, but not yolk sac hematopoietic precursors, isolated before circulation, provide long-term multilineage reconstitution. Immunity 15: 477-485.

Dai XM, Ryan GR, Hapel AJ, Dominguez MG, Russell RG, Kapp S, Sylvestre V, Stanley ER. 2002. Targeted disruption of the mouse colony-stimulating factor 1 receptor gene results in osteopetrosis, mononuclear phagocyte deficiency, increased primitive progenitor cell frequencies, and reproductive defects. Blood 99: 111-120.

Davalos D, Grutzendler J, Yang G, Kim JV, Zuo Y, Jung S, Littman DR, Dustin ML, Gan WB. 2005. ATP mediates rapid microglial response to local brain injury in vivo. Nat Neurosci 8: $752-758$.

Davies LC, Rosas M, Smith PJ, Fraser DJ, Jones SA, Taylor PR. 2011. A quantifiable proliferative burst of tissue macrophages restores homeostatic macrophage populations after acute inflammation. Eur J Immunol 41: 2155-2164.

Delassus S, Cumano A. 1996. Circulation of hematopoietic progenitors in the mouse embryo. Immunity 4: 97-106.

Dickinson RE, Griffin H, Bigley V, Reynard LN, Hussain R, Haniffa M, Lakey JH, Rahman T, Wang XN, McGovern N, et al. 2011. Exome sequencing identifies GATA-2 mutation as the cause of dendritic cell, monocyte, B and NK lymphoid deficiency. Blood 118: 2656-2658.

Diserbo M, Agin A, Lamproglou I, Mauris J, Staali F, Multon E, Amourette C. 2002. Blood-brain barrier permeability after $\gamma$ whole-body irradiation: An in vivo microdialysis study. Can J Physiol Pharmacol 80: 670-678.

Fogg DK, Sibon C, Miled C, Jung S, Aucouturier P, Littman DR, Cumano A, Geissmann F. 2006. A clonogenic bone marrow progenitor specific for macrophages and dendritic cells. Science 311: 83-87.

Geissmann F, Jung S, Littman DR. 2003. Blood monocytes consist of two principal subsets with distinct migratory properties. Immunity 19: 71-82.

Geissmann F, Manz MG, Jung S, Sieweke MH, Merad M, Ley K. 2010. Development of monocytes, macrophages, and dendritic cells. Science 327: 656-661.

Ginhoux F, Greter M, Leboeuf M, Nandi S, See P, Gokhan S, Mehler MF, Conway SJ, Ng LG, Stanley ER, et al. 2010. Fate mapping analysis reveals that adult microglia derive from primitive macrophages. Science 330: 841-845.

Godin IE, Garcia-Porrero JA, Coutinho A, Dieterlen-Lievre F, Marcos MA. 1993. Para-aortic splanchnopleura from early mouse embryos contains B1a cell progenitors. Nature 364: $67-70$.

Godin I, Dieterlen-Lievre F, Cumano A. 1995. Emergence of multipotent hemopoietic cells in the yolk sac and paraaortic splanchnopleura in mouse embryos, beginning at 8.5 days postcoitus. Proc Natl Acad Sci 92: 773-777.

Golde DW, Byers LA, Finley TN. 1974. Proliferative capacity of human alveolar macrophage. Nature 247: 373-375.

Gomez-Nicola D, Fransen NL, Suzzi S, Perry VH. 2013. Regulation of microglial proliferation during chronic neurodegeneration. J Neurosci 33: 2481-2493.

Grage-Griebenow E, Flad HD, Ernst M. 2001. Heterogeneity of human peripheral blood monocyte subsets. J Leukocyte Biol 69: $11-20$.

Hambleton S, Salem S, Bustamante J, Bigley V, Boisson-Dupuis S, Azevedo J, Fortin A, Haniffa M, Ceron-Gutierrez L, Bacon $\mathrm{CM}$, et al. 2011. IRF8 mutations and human dendritic-cell immunodeficiency. New Engl J Med 365: 127-138.

Hashimoto D, Chow A, Noizat C, Teo P, Beasley MB, Leboeuf M, Becker CD, See P, Price J, Lucas D, et al. 2013. Tissueresident macrophages self-maintain locally throughout adult life with minimal contribution from circulating monocytes. Immunity 38: $792-804$.

Herbomel P, Thisse B, Thisse C. 1999. Ontogeny and behaviour of early macrophages in the zebrafish embryo. Development 126: $3735-3745$.

Jamieson AM, Pasman L, Yu S, Gamradt P, Homer RJ, Decker T, Medzhitov R. 2013. Role of tissue protection in lethal respiratory viral-bacterial coinfection. Science 340: 1230-1234.

Jenkins SJ, Ruckerl D, Cook PC, Jones LH, Finkelman FD, van Rooijen N, MacDonald AS, Allen JE. 2011. Local macrophage proliferation, rather than recruitment from the blood, is a signature of TH2 inflammation. Science 332: 1284-1288.

Kanitakis J, Petruzzo P, Dubernard JM. 2004. Turnover of epidermal Langerhans' cells. New Engl J Med 351: 2661 -2662.

Kanitakis J, Morelon E, Petruzzo P, Badet L, Dubernard JM. 2011. Self-renewal capacity of human epidermal Langerhans cells: Observations made on a composite tissue allograft. Exp Dermatol 20: 145-146.

Katz SI, Tamaki K, Sachs DH. 1979. Epidermal Langerhans cells are derived from cells originating in bone marrow. $\mathrm{Na}$ ture 282: 324-326.

Kaya M, Palanduz A, Kalayci R, Kemikler G, Simsek G, Bilgic B, Ahishali B, Arican N, Kocyildiz ZC, Elmas I, et al. 2004. Effects of lipopolysaccharide on the radiation-induced changes in the blood-brain barrier and the astrocytes. Brain Res 1019: $105-112$.

Kierdorf K, Erny D, Goldmann T, Sander V, Schulz C, Perdiguero EG, Wieghofer P, Heinrich A, Riemke P, Holscher C, et al. 2013a. Microglia emerge from erythromyeloid precursors via Pu.1- and Irf8-dependent pathways. Nat Neurosci 16: $273-280$.

Kierdorf K, Katzmarski N, Haas CA, Prinz M. 2013b. Bone marrow cell recruitment to the brain in the absence of irradiation or parabiosis bias. PloS One 8: e58544.

Kieusseian A, Brunet de la Grange P, Burlen-Defranoux O, Godin I, Cumano A. 2012. Immature hematopoietic stem cells undergo maturation in the fetal liver. Development 139: $3521-3530$.

Klein I, Cornejo JC, Polakos NK, John B, Wuensch SA, Topham DJ, Pierce RH, Crispe IN. 2007. Kupffer cell heterogeneity: Functional properties of bone marrow derived and sessile hepatic macrophages. Blood 110: 4077-4085.

Lawson LJ, Perry VH, Gordon S. 1992. Turnover of resident microglia in the normal adult mouse brain. Neuroscience 48: $405-415$.

Li AC, Binder CJ, Gutierrez A, Brown KK, Plotkin CR, Pattison JW, Valledor AF, Davis RA, Willson TM, Witztum JL, et al. 2004. Differential inhibition of macrophage foam-cell formation and atherosclerosis in mice by PPAR $\alpha, \beta / \delta$, and $\gamma$. JClin Invest 114: 1564-1576.

Lieu YK, Reddy EP. 2009. Conditional $c-m y b$ knockout in adult hematopoietic stem cells leads to loss of self-renewal due to 
impaired proliferation and accelerated differentiation. Proc Natl Acad Sci 106: 21689-21694.

Liu K, Waskow C, Liu X, Yao K, Hoh J, Nussenzweig M. 2007. Origin of dendritic cells in peripheral lymphoid organs of mice. Nat Immunol 8: 578-583.

Liu K, Victora GD, Schwickert TA, Guermonprez P, Meredith MM, Yao K, Chu FF, Randolph GJ, Rudensky AY, Nussenzweig M. 2009. In vivo analysis of dendritic cell development and homeostasis. Science 324: 392-397.

Lux CT, Yoshimoto M, McGrath K, Conway SJ, Palis J, Yoder MC. 2008. All primitive and definitive hematopoietic progenitor cells emerging before E10 in the mouse embryo are products of the yolk sac. Blood 111: 3435-3438.

MacDonald KP, Rowe V, Bofinger HM, Thomas R, Sasmono T, Hume DA, Hill GR. 2005. The colony-stimulating factor 1 receptor is expressed on dendritic cells during differentiation and regulates their expansion. J Immunol 175: 1399-1405.

McKenna HJ, Stocking KL, Miller RE, Brasel K, De Smedt T, Maraskovsky E, Maliszewski CR, Lynch DH, Smith J, Pulendran B, et al. 2000. Mice lacking flt3 ligand have deficient hematopoiesis affecting hematopoietic progenitor cells, dendritic cells, and natural killer cells. Blood 95: 3489-3497.

Medvinsky A, Dzierzak E. 1996. Definitive hematopoiesis is autonomously initiated by the AGM region. Cell 86: 897906.

Medvinsky AL, Samoylina NL, Muller AM, Dzierzak EA. 1993. An early pre-liver intraembryonic source of CFU-S in the developing mouse. Nature 364: 64-67.

Medzhitov R. 2008. Origin and physiological roles of inflammation. Nature 454: 428-435.

Merad M, Manz MG, Karsunky H, Wagers A, Peters W, Charo I, Weissman IL, Cyster JG, Engleman EG. 2002. Langerhans cells renew in the skin throughout life under steady-state conditions. Nat Immunol 3: 1135-1141.

Meredith MM, Liu K, Darrasse-Jeze G, Kamphorst AO, Schreiber HA, Guermonprez P, Idoyaga J, Cheong C, Yao $\mathrm{KH}, \mathrm{Niec} \mathrm{RE}$, et al. 2012. Expression of the zinc finger transcription factor zDC (Zbtb46, Btbd4) defines the classical dendritic cell lineage. J Exp Med 209: 1153-1165.

Metchnikoff E. 1884a. The ancestral history of the inflammatory process. Q J Microsc Sci 24: 112-117.

Metchnikoff E. 1884b. Researches on the intracellular digestion of invertebrates. Q J Microsc Sci 24: 89-111.

Mildner A, Schmidt H, Nitsche M, Merkler D, Hanisch UK, Mack M, Heikenwalder M, Bruck W, Priller J, Prinz M. 2007. Microglia in the adult brain arise from Ly- $6 \mathrm{C}^{\text {hi }} \mathrm{CCR} 2^{+}$ monocytes only under defined host conditions. Nat Neurosci 10: $1544-1553$.

Miyauchi S, Hashimoto K. 1987. Epidermal Langerhans cells undergo mitosis during the early recovery phase after ultraviolet-B irradiation. J Invest Dermatol 88: 703-708.

Moore KJ, Tabas I. 2011. Macrophages in the pathogenesis of atherosclerosis. Cell 145: 341-355.

Mucenski ML, McLain K, Kier AB, Swerdlow SH, Schreiner CM, Miller TA, Pietryga DW, Scott WJ Jr, Potter SS. 1991. A functional $c-m y b$ gene is required for normal murine fetal hepatic hematopoiesis. Cell 65: 677-689.

Mukouyama Y, Chiba N, Mucenski ML, Satake M, Miyajima A, Hara T, Watanabe T. 1999. Hematopoietic cells in cultures of the murine embryonic aorta-gonad-mesonephros region are induced by $c-M y b$. Curr Biol 9: 833-836.

Muller AM, Medvinsky A, Strouboulis J, Grosveld F, Dzierzak E. 1994. Development of hematopoietic stem cell activity in the mouse embryo. Immunity 1: 291-301.

Naito M. 2008. Macrophage differentiation and function in health and disease. Pathol Int 58: 143-155.

Naito M, Umeda S, Yamamoto T, Moriyama H, Umezu H, Hasegawa G, Usuda H, Shultz LD, Takahashi K. 1996. Development, differentiation, and phenotypic heterogeneity of murine tissue macrophages. J Leukocyte Biol 59: 133-138.

Nimmerjahn A, Kirchhoff F, Helmchen F. 2005. Resting microglial cells are highly dynamic surveillants of brain parenchyma in vivo. Science 308: 1314-1318.
Nishikawa SI, Nishikawa S, Kawamoto H, Yoshida H, Kizumoto M, Kataoka H, Katsura Y. 1998. In vitro generation of lymphohematopoietic cells from endothelial cells purified from murine embryos. Immunity 8: 761-769.

Onai N, Obata-Onai A, Schmid MA, Ohteki T, Jarrossay D, Manz MG. 2007. Identification of clonogenic common Flt3 ${ }^{+}$ M-CSFR ${ }^{+}$plasmacytoid and conventional dendritic cell progenitors in mouse bone marrow. Nat Immunol 8: 1207-1216.

Palis J, Chan RJ, Koniski A, Patel R, Starr M, Yoder MC. 2001. Spatial and temporal emergence of high proliferative potential hematopoietic precursors during murine embryogenesis. Proc Natl Acad Sci 98: 4528-4533.

Paolicelli RC, Bolasco G, Pagani F, Maggi L, Scianni M, Panzanelli P, Giustetto M, Ferreira TA, Guiducci E, Dumas L, et al. 2011. Synaptic pruning by microglia is necessary for normal brain development. Science 333: 1456-1458.

Perreault C, Pelletier M, Landry D, Gyger M. 1984. Study of Langerhans cells after allogeneic bone marrow transplantation. Blood 63: 807-811.

Pforte A, Gerth C, Voss A, Beer B, Haussinger K, Jutting U, Burger G, Ziegler-Heitbrock HW. 1993. Proliferating alveolar macrophages in BAL and lung function changes in interstitial lung disease. Eur Respir J 6: 951-955.

Qian BZ, Li J, Zhang H, Kitamura T, Zhang J, Campion LR, Kaiser EA, Snyder LA, Pollard JW. 2011. CCL2 recruits inflammatory monocytes to facilitate breast-tumour metastasis. Nature 475: 222-225.

Rae F, Woods K, Sasmono T, Campanale N, Taylor D, Ovchinnikov DA, Grimmond SM, Hume DA, Ricardo SD, Little MH. 2007. Characterisation and trophic functions of murine embryonic macrophages based upon the use of a Csflr-EGFP transgene reporter. Dev Biol 308: 232-246.

Rampon C, Huber P. 2003. Multilineage hematopoietic progenitor activity generated autonomously in the mouse yolk sac: Analysis using angiogenesis-defective embryos. Int $J$ Dev Biol 47: 273-280.

Saijo K, Winner B, Carson CT, Collier JG, Boyer L, Rosenfeld MG, Gage FH, Glass CK. 2009. A Nurr1/CoREST pathway in microglia and astrocytes protects dopaminergic neurons from inflammation-induced death. Cell 137: 47-59.

Sasmono RT, Oceandy D, Pollard JW, Tong W, Pavli P, Wainwright BJ, Ostrowski MC, Himes SR, Hume DA. 2003. A macrophage colony-stimulating factor receptor-green fluorescent protein transgene is expressed throughout the mononuclear phagocyte system of the mouse. Blood 101: 1155-1163.

Sawyer RT, Strausbauch PH, Volkman A. 1982. Resident macrophage proliferation in mice depleted of blood monocytes by strontium-89. Lab Invest 46: 165-170.

Schulz C, Gomez Perdiguero E, Chorro L, Szabo-Rogers H, Cagnard N, Kierdorf K, Prinz M, Wu B, Jacobsen SE, Pollard JW, et al. 2012. A lineage of myeloid cells independent of $M y b$ and hematopoietic stem cells. Science 336: 86-90.

Serbina NV, Pamer EG. 2006. Monocyte emigration from bone marrow during bacterial infection requires signals mediated by chemokine receptor CCR2. Nat Immunol 7: 311-317.

Serbina NV, Jia T, Hohl TM, Pamer EG. 2008. Monocyte-mediated defense against microbial pathogens. Anпи Rev Immunol 26: $421-452$.

Shankaran M, Marino ME, Busch R, Keim C, King C, Lee J, Killion S, Awada M, Hellerstein MK. 2007. Measurement of brain microglial proliferation rates in vivo in response to neuroinflammatory stimuli: Application to drug discovery. J Neurosci Res 85: 2374-2384.

Sorokin SP, Hoyt RF Jr, Blunt DG, McNelly NA. 1992. Macrophage development: II. Early ontogeny of macrophage populations in brain, liver, and lungs of rat embryos as revealed by a lectin marker. Anat Rec 232: 527-550.

Soudja SM, Ruiz AL, Marie JC, Lauvau G. 2012. Inflammatory monocytes activate memory $\mathrm{CD} 8^{+} \mathrm{T}$ and innate NK lymphocytes independent of cognate antigen during microbial pathogen invasion. Immunity 37: 549-562.

Spann NJ, Garmire LX, McDonald JG, Myers DS, Milne SB, Shibata N, Reichart D, Fox JN, Shaked I, Heudobler D, et al. 
2012. Regulated accumulation of desmosterol integrates macrophage lipid metabolism and inflammatory responses. Cell 151: $138-152$.

Srinivas S, Watanabe T, Lin CS, William CM, Tanabe Y, Jessell TM, Costantini F. 2001. Cre reporter strains produced by targeted insertion of EYFP and ECFP into the ROSA26 locus. BMC Dev Biol 1: 4.

Sumner R, Crawford A, Mucenski M, Frampton J. 2000. Initiation of adult myelopoiesis can occur in the absence of $c-M y b$ whereas subsequent development is strictly dependent on the transcription factor. Oncogene 19: 3335-3342.

Thomas ED, Ramberg RE, Sale GE, Sparkes RS, Golde DW. 1976. Direct evidence for a bone marrow origin of the alveolar macrophage in man. Science 192: 1016-1018.

Thored P, Heldmann U, Gomes-Leal W, Gisler R, Darsalia V, Taneera J, Nygren JM, Jacobsen SE, Ekdahl CT, Kokaia Z, et al. 2009. Long-term accumulation of microglia with proneurogenic phenotype concomitant with persistent neurogenesis in adult subventricular zone after stroke. Glia 57: 835849.

Tsou CL, Peters W, Si Y, Slaymaker S, Aslanian AM, Weisberg SP, Mack M, Charo IF. 2007. Critical roles for CCR2 and MCP-3 in monocyte mobilization from bone marrow and recruitment to inflammatory sites. J Clin Invest 117: 902-909.

Ueno H, Weissman IL. 2010. The origin and fate of yolk sac hematopoiesis: Application of chimera analyses to developmental studies. Int J Dev Biol 54: 1019-1031.

van Furth R, Cohn ZA. 1968. The origin and kinetics of mononuclear phagocytes. $J$ Exp Med 128: 415-435.

van Furth R, Cohn ZA, Hirsch JG, Humphrey JH, Spector WG, Langevoort HL. 1972. The mononuclear phagocyte system: A new classification of macrophages, monocytes, and their precursor cells. Bull World Health Organ 46: 845-852.
Wake H, Moorhouse AJ, Jinno S, Kohsaka S, Nabekura J. 2009. Resting microglia directly monitor the functional state of synapses in vivo and determine the fate of ischemic terminals. J Neurosci 29: 3974-3980.

Waskow C, Liu K, Darrasse-Jèze G, Guermonprez P, Ginhoux F, Merad M, Shengelia T, Yao K, Nussenzweig M. 2008. The receptor tyrosine kinase Flt3 is required for dendritic cell development in peripheral lymphoid tissues. Nat Immunol 9: $676-683$

Weissman IL, Warnke R, Butcher EC, Rouse R, Levy R. 1978. The lymphoid system. Its normal architecture and the potential for understanding the system through the study of lymphoproliferative diseases. Hum Pathol 9: 25-45.

Winston DJ, Territo MC, Ho WG, Miller MJ, Gale RP, Golde DW. 1982. Alveolar macrophage dysfunction in human bone marrow transplant recipients. Am $J$ Med 73: 859-866.

Yamada M, Naito M, Takahashi K. 1990. Kupffer cell proliferation and glucan-induced granuloma formation in mice depleted of blood monocytes by strontium-89. J Leukocyte Biol 47: 195-205.

Yoder MC, Hiatt K. 1997. Engraftment of embryonic hematopoietic cells in conditioned newborn recipients. Blood 89: 2176-2183.

Yona S, Kim KW, Wolf Y, Mildner A, Varol D, Breker M, Strauss-Ayali D, Viukov S, Guilliams M, Misharin A, et al. 2013. Fate mapping reveals origins and dynamics of monocytes and tissue macrophages under homeostasis. Immunity 38: 79-91.

Zovein AC, Turlo KA, Ponec RM, Lynch MR, Chen KC, Hofmann JJ, Cox TC, Gasson JC, Iruela-Arispe ML. 2010. Vascular remodeling of the vitelline artery initiates extravascular emergence of hematopoietic clusters. Blood 116: $3435-$ 3444 . 


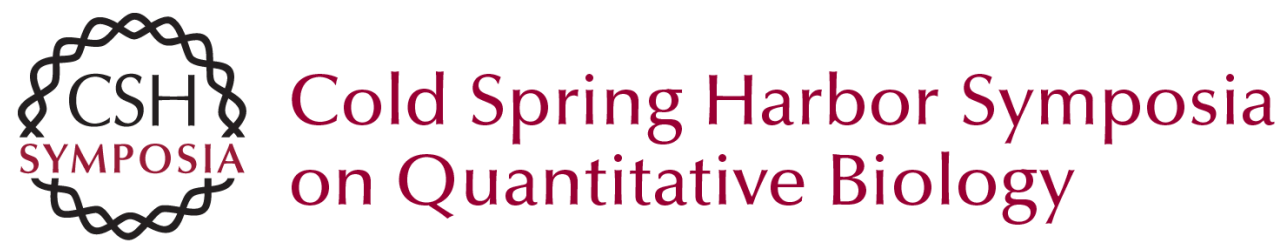

\section{Myb-Independent Macrophages: A Family of Cells That Develops with Their Tissue of Residence and Is Involved in Its Homeostasis}

Elisa Gomez Perdiguero and Frederic Geissmann

Cold Spring Harb Symp Quant Biol 2013 78: 91-100 originally published online October 11, 2013 Access the most recent version at doi:10.1101/sqb.2013.78.020032

References This article cites 107 articles, 36 of which can be accessed free at: http://symposium.cshlp.org/content/78/91.full.html\#ref-list-1

\section{License}

Email Alerting Receive free email alerts when new articles cite this article - sign up in Service the box at the top right corner of the article or click here. 